\title{
Changes in Grip Strength and Associations with Grip Strength in Breast Cancer Survivors Treated with Adjuvant Chemotherapy
}

\author{
Seongwook Son, Changbae Lee, Ju Yeon Lee, Dong Seok Yang, Chung Reen Kim \\ Department of Physical Medicine and Rehabilitation, University of Ulsan College of Medicine, Ulsan, Korea
}

Purpose: The aim of this study was to identify the change in hand grip strength (HGS) for consecutive 6 months in breast cancer survivors (BCS) undergoing postoperative adjuvant chemotherapy (adjCTX) and to determine the factors relevant to HGS after chemotherapy completion

Methods: This study was a retrospective observational cohort study. BCS $(\mathrm{N}=38)$ who underwent breast cancer surgery and subsequent adjCTX were enrolled. The HGS of both sides was measured before adjCTX and 3 weeks, 2 months and 6 months after adjCTX. And we also collected body composition, anthropometric measurements, social demographics and clinical data. Then we analyzed the changes in HGS over time, and correlation of collected data with HGS at 6 months.

Results: A significant increase in HGS of the unaffected side was observed within the first 3 weeks of adjCTX and maintained up to 6 months. In correlation analysis, HGS of both sides was positively correlated with the ipsilateral HGS at 3 weeks, and contralateral HGS at 6 months. And skeletal muscle mass was also positively correlated with the HGS of the unaffected side. In addition, subjects treated with targeted therapy had lower HGS of the unaffected side. However, HGS of the affected side was significantly lower in subjects with breast reconstruction and treated without radiotherapy.

Conclusions: To maintain the early recovery of HGS, active and continuous exercise intervention for strengthening might be necessary.

Keywords: Breast cancer, Hand strengths, Adjuvant chemotherapy

\section{INTRODUCTION}

Breast cancer is one of the most common cancer diseases in women. ${ }^{1}$ Development of cancer treatment has increased the high 5-year survival rate to about $90 \% .{ }^{2}$ Due to the high survival rate, interest is increasing in the quality of life of BCS. ${ }^{3}$ However, in the long term, various treatments such as adjuvant chemotherapy (adjCTX), radiotherapy, hormonal therapy (HT), and targeted therapy (TT) are administered to BCS. In addition, these treatments often cause several side effects such as fatigue, pain, and depression, ${ }^{4-6}$ which impedes recovery to normal life. ${ }^{7}$ Therefore, breast cancer survivors (BCS) become a major concern in cancer rehabilitation

To address those issues, it is important to know the exact physical condition of BCS. Hand grip strength (HGS) has been widely used as an easy and useful way to indirectly assess physical strength. Par-

Received Jun 9, 2020 Revised Jun 17, 2020

Accepted Jun 29, 2020

Corresponding author Chung Reen Kim

E-mail crkim@uuh.ulsan.kr ticularly, in the case of unilateral breast cancer patients, it is advantageous to compare the grip strength of both sides. Therefore, through several studies, the relationship between HGS and the prognosis of BCS has been already reported ${ }^{8-10}$ However, these were mainly cross-sectional studies that evaluated HGS at a specific time point before or after surgery, or were followed up at long intervals. However, in our clinical experience, we observed changes in the muscle strength of BCS, especially in the early stages of adjuvant chemotherapy. Moreover, it was reported that muscle strength during the subacute postoperative period could affect muscle strength several years later. ${ }^{11}$

We thought that understanding the pattern of changes in HGS within the first few months after surgery is important in identifying the long-term prognosis. However, there were no relevant reports for this time period in BCS. Therefore, in this study, we analyzed

Copylight $(02020$ The Korean Society of Physical Therapy

This is an Open Access article distribute under the terms of the Creative Commons Attribution Non-commercial License (https:// creativecommons.org/license/by-nc/4.0.) which permits unrestricted non-commercial use, distribution, and reproduction in any medium, provided the original work is properly cited. 
the changes in HGS for 6 consecutive months in BCS undergoing postoperative adjCTX. In addition, we evaluated the factors that were related to HGS after chemotherapy completion and factors that should be considered to maintain high HGS. Thus, this study might be helpful in suggesting the interventions that should be emphasized in BCS during the adjCTX and subsequent therapies.

\section{METHODS}

\section{Subjects}

This retrospective observational cohort study was performed in patients who underwent adjCTX for breast cancer at 000 Hospital from January 2018 to February 2019. Ethical clearance was granted by the institutional review board. The subjects included in this study were between 25 and 75 years of age with a single breast operation and a pathologically confirmed diagnosis of stage I to III. The exclusion criteria were as follows: 1) received neoadjuvant chemotherapy; 2) significant cardiac, pulmonary, or metabolic comorbidities; 3) previous breast cancer diagnosis and treatment of the ipsilateral or contralateral sides; and 4) difficulty measuring HGS due to musculoskeletal and neurological diseases.

\section{Variables and measurement}

In addition to HGS, anthropometric and body composition data just before adjCTX and 3 weeks, 2 months, and 6 months after adjCTX were collected. And other socio-demographic and clinical characteristics were also obtained.

\section{1) Socio-demographic and clinical variables}

Socio-demographic characteristics of participants including age, marital status, level of education, employment status, and smoking and drinking history were collected from medical records. Additionally, clinical characteristics of participants including cancer stage, affected and dominant limb, type of breast and lymph node surgery, type of adjuvant treatment, and presence of lymphedema were recorded.

\section{2) Hand grip strength}

A calibrated dynamometer was used to assess HGS (Hydraulic Hand Dynamometer SH5001, Saehan, Masan, Korea). HGS was measured by a trained occupational therapist. The shoulder was ad- ducted and neutrally rotated with the elbow at a $90^{\circ}$ flexion, and the forearm and wrist in a neutral position. The participants were asked to squeeze the handle for a maximum of 3-5seconds. Three trials were alternately performed on each side with a rest period of at least 1 minute between trials of the same hand. This test is valid and reliable. ${ }^{12}$

\section{3) Anthropometric and body composition variables}

The anthropometric data such as height, weight, and body mass index (BMI) were collected at each evaluation point. The BMI was calculated as weight $(\mathrm{kg})$ divided by height squared $\left(\mathrm{m}^{2}\right)$. An experienced physiotherapist used bioimpedance analysis (BIA, InBodyS10, Biospace, Seoul, Korea) to skeletal muscle mass (SMM) and skeletal muscle index (SMI)(SMM/height $\left.{ }^{2}\right)$. For this, the patient with an empty bladder was placed in a supine position on a nonconducting stable surface, the wrist and ankle ornaments were removed, and the gel was applied to fingers and ankles to reduce skin resistance.

\section{Statistical analysis}

Statistical analyses were performed using SPSS v.24.0 (IBM, Inc., Chicago, IL, USA). The normality of distributions was tested by the Kolmogorov-Smirnov method. Repeated measures one-way analysis of variance (ANOVA) was performed to analyze changes in HGS of the affected and unaffected side, SMM, SMI, weight, and BMI followed by Tukey's posthoc tests. To identify the factors that were significantly associated with HGS at 6 months, univariate and multivariate linear analyses were performed using the stepwise method. Sociodemographic and clinical characteristics were compared using Student's t-test or one-way ANOVA if normality was satisfied. If not, Mann-Whitney U or Kruskal-Wallis test was used. A p-value of $<0.05$ was considered statistically significant.

\section{RESULTS}

\section{General characteristics}

Out of 157 subjects, 38 subjects who satisfied the inclusion and exclusion criteria were analyzed (Figure 1). The mean age at the beginning of adjCTX was 54.63 years, and 12 and 7 patients had left and right breast cancer, respectively. Other sociodemographic and clinical characteristics are presented in Table 1. 


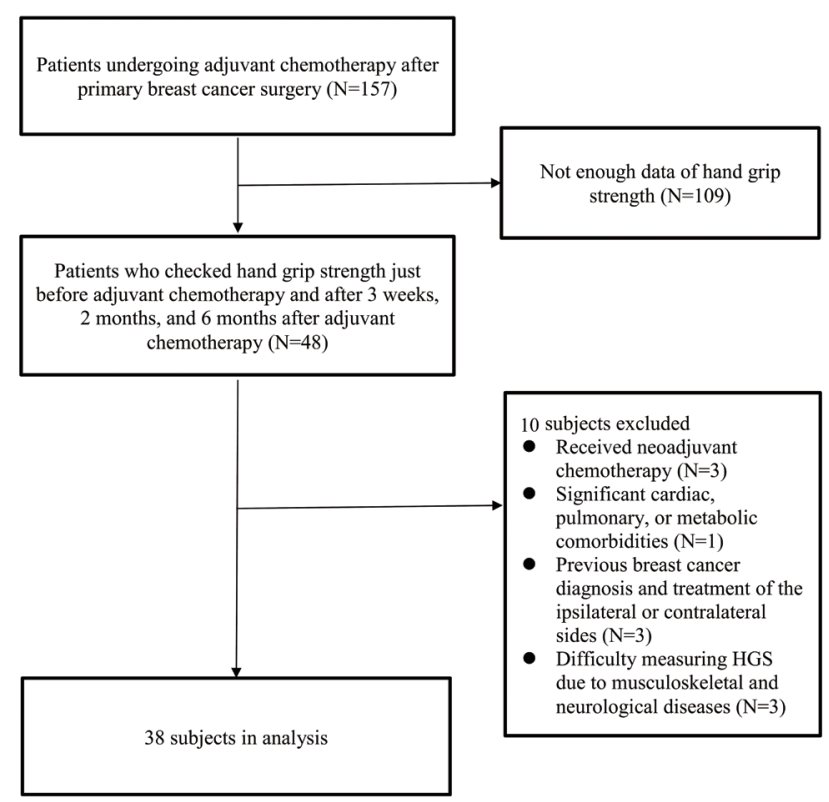

Figure 1. STROBE diagram for depicting participant flow.

\section{Changes in HGS}

HGS of the affected side (the same side as surgery) was not significant but showed a tendency to increase during follow-up (Table 2, Figure 2). However, there was a significant change in the HGS of the unaffected side and the HGS at 3 weeks, 2 months, and 6 months were higher than that at baseline. A clear change was observed until the first 3 weeks. However, no significant difference was observed between the affected and unaffected sides $(\mathrm{p}=0.527)$.

\section{Relationship between $\mathrm{HGS}$ at 6 months and variables}

In univariate linear regression analysis, the variables that were significantly associated with HGS of the affected side at 6 months were bilateral HGS at baseline, 3 weeks, and 2 months; contralateral HGS at 6 months; and SMM and SMI at 2 and 6 months (Table 3). The HGS of the unaffected side had a significant correlation with ipsilateral HGS at baseline, 3 weeks, and 6 months; contralateral HGS and SMM at 3 weeks, 2 months, and 6 months; and weight and SMI at 2 and 6 months (Table 4).

When performing multivariate regression analysis with above relevant variables, HGS of the affected side was positively correlated to ipsilateral HGS at 3 weeks, and contralateral HGS at 6 months (Table 3). HGS of the unaffected side showed a positive correlation with the ipsilateral HGS at 3 weeks, and contralateral HGS and SMM at 6 months (Table 4). There were negative correlations between con-

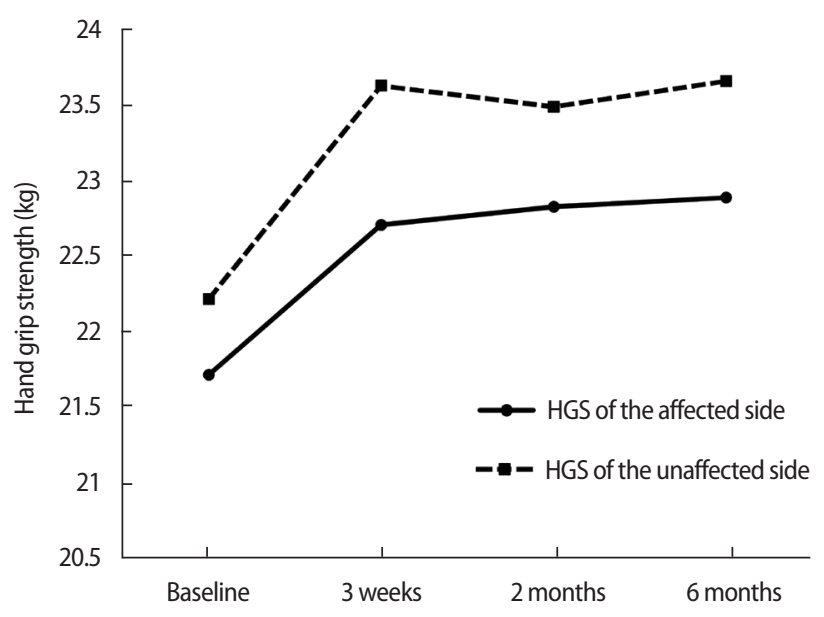

Figure 2. Changes in hand grip strength of the affected and unaffected side according to the time.

tralateral HGS at 3 weeks and 6 months.

Socio-demographic variables such as dominant hand, marital status, education level, employment, and smoking and alcohol history were not significantly different between sub-variables (Table 1). There was no significant difference of HGS in clinical variables such as cancer stage, type of surgery, chemotherapy regimen, hormone therapy, and presence of lymphedema in either the affected or unaffected side (Table 1). On the unaffected side, however, lower HGS was observed in subjects treated with TT $(\mathrm{p}=0.033)$ than in those who were not treated with TT. However, HGS of the affected side was significantly lower in subjects who underwent breast reconstruction and were treated without radiotherapy $(\mathrm{p}=0.045$ and $\mathrm{p}=0.045$, respectively).

\section{DISCUSSION}

It is well-known that HGS after surgery is generally not restored during adjuvant therapy in BCS. ${ }^{9,13,14}$ However, the results of this study showed that HGS was not only observed the linear trend of decline. A significant increase in HGS of the unaffected side was observed within the first 3 weeks of adjCTX and maintained up to 6 months. In addition, the factors that were significantly related to HGS in the general population were not as relevant in BCS. Above all, HGS itself was associated with a consistently higher HGS, and the correlation between left and right sides was also observed. And cancer therapies such as TT and breast reconstruction were also related to HGS in BCS. 
Table 1. Socio-demographic and clinical characteristics of subjects

\begin{tabular}{|c|c|c|c|c|c|}
\hline \multirow{2}{*}{ Variables } & \multirow{2}{*}{$\begin{array}{c}N=38 \\
(\%)\end{array}$} & \multicolumn{2}{|c|}{ HGS of the affected side $(\mathrm{kg})$} & \multicolumn{2}{|c|}{ HGS of the unaffected side $(\mathrm{kg})$} \\
\hline & & Mean $\pm S D$ & $p$-value & Mean $\pm S D$ & $\mathrm{p}$-value \\
\hline $\begin{array}{l}\text { Age at the fist adjuvant } \\
\text { chemotherapy session (yr) }\end{array}$ & $54.63 \pm 7.78$ & & & & \\
\hline $\begin{array}{l}\text { Time from surgery to the first } \\
\text { adjuvant chemotherapy session (day) }\end{array}$ & $29.36 \pm 6.57$ & & & & \\
\hline Length of follow-up (day) & $184.53 \pm 13.21$ & & & & \\
\hline \multicolumn{6}{|l|}{ Level of education } \\
\hline$\leq 6 \mathrm{yr}$ & $7(18.4)$ & $21.69 \pm 4.32$ & 0.815 & $21.96 \pm 4.07$ & 0.599 \\
\hline $6-12 \mathrm{yr}$ & $24(63.2)$ & $23.10 \pm 5.99$ & & $23.83 \pm 5.78$ & \\
\hline$\geq 12 \mathrm{yr}$ & $7(18.4)$ & $23.33 \pm 4.70$ & & $24.76 \pm 4.50$ & \\
\hline \multicolumn{6}{|l|}{ Marital status } \\
\hline Married & $37(97.3)$ & $22.82 \pm 5.47$ & 0.667 & $23.67 \pm 5.32$ & 0.902 \\
\hline Unmarried & $0(0)$ & - & & - & \\
\hline Divorced/widowed & $1(2.7)$ & 25.3 & & 23 & \\
\hline \multicolumn{6}{|l|}{ Employment } \\
\hline Home employed & $21(55.3)$ & $21.96 \pm 4.61$ & 0.138 & $22.97 \pm 4.85$ & 0.263 \\
\hline Employed & $13(34.2)$ & $25.20 \pm 6.20$ & & $25.48 \pm 5.50$ & \\
\hline Non-employed & $4(10.5)$ & $20.23 \pm 2.60$ & & $21.33 \pm 6.06$ & \\
\hline \multicolumn{6}{|l|}{ Smoking history } \\
\hline Never & $37(97.3)$ & $23.76 \pm 5.28$ & 0.838 & $22.85 \pm 5.48$ & 0.453 \\
\hline Ex-smoker & $0(0)$ & - & & - & \\
\hline Current smoker & $1(2.7)$ & 19.7 & & 24 & \\
\hline \multicolumn{6}{|l|}{ Alcohol history } \\
\hline Never & $36(94.7)$ & $22.63 \pm 5.40$ & 0.236 & $23.50 \pm 5.11$ & 0.463 \\
\hline Socially & $2(5.3)$ & $27.35 \pm 4.74$ & & $26.35 \pm 9.40$ & \\
\hline Heavy alcoholics & $0(0)$ & - & & - & \\
\hline \multicolumn{6}{|l|}{ Dominant hand } \\
\hline Right & 30 (78.9) & $22.36 \pm 5.71$ & 0.250 & $22.90 \pm 5.22$ & 0.085 \\
\hline Left & $8(21.1)$ & $24.86 \pm 3.72$ & & $26.49 \pm 4.59$ & \\
\hline \multicolumn{6}{|l|}{ Cancer location } \\
\hline Right breast & $13(34.2)$ & $21.75 \pm 3.36$ & 0.360 & $20.25 \pm 2.30$ & $<0.001^{*}$ \\
\hline Left breast & $25(65.8)$ & $23.47 \pm 6.20$ & & $25.42 \pm 5.50$ & \\
\hline \multicolumn{6}{|l|}{ Cancer stage } \\
\hline I & $17(44.7)$ & $22.84 \pm 7.14$ & 0.667 & $24.23 \pm 6.22$ & 0.498 \\
\hline$\| \mathrm{A}$ & $11(28.9)$ & $24.31 \pm 2.67$ & & $24.76 \pm 4.48$ & \\
\hline$\| \mathrm{B}$ & $5(13.2)$ & $20.80 \pm 5.31$ & & $21.38 \pm 4.71$ & \\
\hline IIIA & $5(13.2)$ & $21.98 \pm 3.02$ & & $21.52 \pm 3.23$ & \\
\hline \multicolumn{6}{|l|}{ Breast surgery } \\
\hline Breast conserving operation & $24(63.2)$ & $23.53 \pm 5.90$ & 0.604 & $24.00 \pm 5.54$ & 0.340 \\
\hline Mastectomy & $14(36.8)$ & $21.77 \pm 4.44$ & & $23.06 \pm 4.85$ & \\
\hline \multicolumn{6}{|l|}{ Lymph node surgery } \\
\hline Axillary lymph node dissection & $17(44.7)$ & $21.69 \pm 3.59$ & 0.203 & $22.01 \pm 3.51$ & 0.068 \\
\hline Sentinel node biopsy & $21(55.3)$ & $23.85 \pm 6.46$ & & $24.98 \pm 6.08$ & \\
\hline \multicolumn{6}{|l|}{ Breast reconstruction } \\
\hline No & $26(68.4)$ & $24.07 \pm 5.45$ & $0.045^{*}$ & $24.29 \pm 5.30$ & 0.274 \\
\hline Yes & $12(31.6)$ & $20.32 \pm 4.55$ & & $22.27 \pm 5.12$ & \\
\hline \multicolumn{6}{|l|}{ Adjuvant chemotherapy } \\
\hline Doxorubicin with taxane & $6(15.8)$ & $21.82 \pm 4.47$ & 0.456 & $23.27 \pm 1.39$ & 0.770 \\
\hline Doxorubicin without taxane & $3(7.9)$ & $19.63 \pm 4.93$ & & $21.67 \pm 5.05$ & \\
\hline Taxane without doxorubicin & $29(76.3)$ & $23.94 \pm 1.05$ & & $23.94 \pm 5.85$ & \\
\hline
\end{tabular}


Table 1. Continued

\begin{tabular}{|c|c|c|c|c|c|}
\hline \multirow{2}{*}{ Variables } & \multirow{2}{*}{$\begin{array}{c}N=38 \\
(\%)\end{array}$} & \multicolumn{2}{|c|}{ HGS of the affected side (kg) } & \multicolumn{2}{|c|}{ HGS of the unaffected side $(\mathrm{kg})$} \\
\hline & & Mean \pm SD & $\mathrm{p}$-value & Mean \pm SD & $\mathrm{p}$-value \\
\hline \multicolumn{6}{|c|}{ Numbers of chemotherapy session } \\
\hline 4 & $28(73.7)$ & $23.11 \pm 5.84$ & 0.875 & $23.83 \pm 5.67$ & 0.939 \\
\hline 6 & $4(10.5)$ & $22.90 \pm 4.38$ & & $22.98 \pm 5.42$ & \\
\hline 8 & $6(15.8)$ & $21.82 \pm 4.45$ & & $23.27 \pm 3.41$ & \\
\hline \multicolumn{6}{|c|}{ Hormonal therapy } \\
\hline No & $11(28.9)$ & $24.64 \pm 6.89$ & 0.207 & $24.90 \pm 5.70$ & 0.357 \\
\hline Yes & $27(71.1)$ & $22.17 \pm 4.65$ & & $23.14 \pm 5.07$ & \\
\hline \multicolumn{6}{|c|}{ Radiotherapy } \\
\hline No & $12(31.6)$ & $20.32 \pm 4.55$ & $0.045^{*}$ & $22.27 \pm 5.12$ & 0.274 \\
\hline Yes & $26(68.4)$ & $24.07 \pm 5.45$ & & $24.29 \pm 5.30$ & \\
\hline \multicolumn{6}{|c|}{ Targeted therapy } \\
\hline No & 15 (39.5) & $24.37 \pm 6.44$ & 0.174 & $25.89 \pm 5.49$ & $0.033^{*}$ \\
\hline Yes & $23(60.5)$ & $21.91 \pm 4.51$ & & $22.20 \pm 4.64$ & \\
\hline \multicolumn{6}{|c|}{ Presence of lymphedema } \\
\hline No & $34(89.5)$ & $22.81 \pm 5.69$ & 0.799 & $23.59 \pm 5.48$ & 0.844 \\
\hline Yes & $4(10.5)$ & $23.56 \pm 2.06$ & & $24.15 \pm 2.91$ & \\
\hline
\end{tabular}

Values are mean \pm standard deviation.

${ }^{*} p<0.05$ is significant by comparison osub-variables at each side.

Table 2. Changes of hand grip strength, anthropometric and body composition variables

\begin{tabular}{|c|c|c|c|c|c|c|}
\hline \multirow{2}{*}{ Variables } & \multicolumn{4}{|c|}{ Follow-up periods } & \multirow{2}{*}{$\begin{array}{c}\text { p-value } \\
\text { within group }\end{array}$} & \multirow{2}{*}{ Posthoc by Turkey tests } \\
\hline & Baseline & 3 weeks & 2 months & 6 months & & \\
\hline HGS of the affected side $(\mathrm{kg})$ & $21.71 \pm 4.49$ & $22.70 \pm 5.71$ & $22.82 \pm 4.94$ & $22.88 \pm 5.41$ & 0.064 & 2 months $>$ Baseline \\
\hline HGS of the unaffected side $(\mathrm{kg})$ & $22.21 \pm 4.89$ & $23.62 \pm 5.63$ & $23.48 \pm 5.22$ & $23.65 \pm 5.20$ & $0.009 *$ & $\begin{array}{l}3 \text { weeks }>\text { Baseline, } 2 \text { months }>\text { Baseline, } \\
6 \text { months }>\text { Baseline }\end{array}$ \\
\hline Height $(\mathrm{cm})$ & $157.18 \pm 6.76$ & - & - & - & & \\
\hline Body weight $(\mathrm{kg})$ & $60.32 \pm 9.23$ & $60.79 \pm 9.30$ & $61.37 \pm 9.51$ & $60.12 \pm 9.21$ & $<0.001^{*}$ & $\begin{array}{l}3 \text { weeks }>\text { Baseline, } 2 \text { months }>\text { Baseline, } \\
2 \text { months }>3 \text { weeks, } 3 \text { weeks }>6 \text { months, } \\
2 \text { months }>6 \text { months }\end{array}$ \\
\hline Body mass index $\left(\mathrm{kg} / \mathrm{m}^{2}\right)$ & $24.48 \pm 3.97$ & $24.71 \pm 3.99$ & $24.90 \pm 4.08$ & $24.41 \pm 3.80$ & $<0.001^{*}$ & $\begin{array}{l}3 \text { weeks }>\text { Baseline, } 2 \text { months }>\text { Baseline, } \\
2 \text { months }>3 \text { weeks, } 3 \text { weeks }>6 \text { months, } \\
2 \text { months }>6 \text { months }\end{array}$ \\
\hline Skeletal muscle mass (kg) & $21.51 \pm 3.27$ & $21.77 \pm 3.31$ & $21.27 \pm 2.57$ & $20.96 \pm 2.67$ & $0.004^{*}$ & 3 weeks $>$ Baseline, 3 weeks $>6$ months \\
\hline Skeletal muscle index $\left(\mathrm{kg} / \mathrm{m}^{2}\right)$ & $8.71 \pm 1.28$ & $8.83 \pm 1.30$ & $8.61 \pm 0.83$ & $8.48 \pm 0.77$ & $0.004^{*}$ & 3 weeks $>$ Baseline, 3 weeks $>6$ months \\
\hline
\end{tabular}

Values are mean \pm standard deviation.

HGS: hand grip strength.

${ }^{*} p<0.05$ is significant.

In the case of the unaffected side, HGS increased significantly during the first 3 weeks after adjCTX, which was about 2 months after the surgery. It seemed that the early postoperative period was important for the recovery of muscle strength despite the initiation of adjCTX. Moreover, another previous study that observed long term changes in physical activity showed that a gradual increase in activity began 1 month postoperatively. ${ }^{15}$ Thus, the intrinsic power to recover the body seemed to begin in the early postoperative period. Additionally, although adjCTX is well-known to have myotoxic effects ${ }^{16}$ our results showed that a single session of adjCTX did not cause severe myotoxicity.

Unfortunately, the early HGS recovery did not continue after 3 weeks of adjCTX. The stagnation might be due to the accumulation of chemotoxicity. Commonly used anticancer drugs such as doxorubicin, cyclophosphamide, and taxanes are known to cause severe reductions in myofiber size, neurogenic alterations, and mitochondria-related damages ${ }^{16}$ which clinically lead to increased weakness and muscular fatigue. ${ }^{13}$ Moreover, repeated chemotherapy inter- 
Table 3. Univariate and multivariate linear regression analysis of hand grip strength of the affected side at 6 months

\begin{tabular}{|c|c|c|c|c|}
\hline \multirow{2}{*}{ Variables } & \multicolumn{2}{|c|}{ Univariate analysis } & \multicolumn{2}{|c|}{ Multivariate analysis $\left.(n=38)^{a}\right)$} \\
\hline & Standardized Beta & $\mathrm{p}$-value & Standardized Beta & p-value \\
\hline \multicolumn{5}{|l|}{ Baseline } \\
\hline Age & -0.288 & 0.080 & & \\
\hline Height & 0.316 & 0.053 & & \\
\hline HGS of the affected side & 0.749 & $<0.001^{*}$ & & \\
\hline HGS of the unaffected side & 0.630 & $<0.001^{*}$ & & \\
\hline Weight & 0.170 & 0.315 & & \\
\hline BMI & -0.037 & 0.828 & & \\
\hline SMM & 0.250 & 0.135 & & \\
\hline SMI & 0.049 & 0.775 & & \\
\hline \multicolumn{5}{|l|}{3 weeks } \\
\hline HGS of the affected side & 0.862 & $<0.001^{*}$ & 0.693 & $<0.001^{*}$ \\
\hline HGS of the unaffected side & 0.674 & $<0.001^{*}$ & -0.474 & $0.001^{*}$ \\
\hline Weight & 0.157 & 0.347 & & \\
\hline BMI & 0.232 & 0.162 & & \\
\hline SMM & 0.030 & 0.996 & & \\
\hline SMl & 0.026 & 0.878 & & \\
\hline \multicolumn{5}{|l|}{2 months } \\
\hline HGS of the affected side & 0.824 & $<0.001^{*}$ & & \\
\hline HGS of the unaffected side & 0.735 & $<0.001^{*}$ & & \\
\hline Weight & 0.204 & 0.220 & & \\
\hline BMI & -0.014 & 0.933 & & \\
\hline SMM & 0.594 & $<0.001^{*}$ & & \\
\hline SMI & 0.431 & $0.007^{\star}$ & & \\
\hline \multicolumn{5}{|l|}{6 months } \\
\hline HGS of the unaffected side & 0.828 & $<0.001^{*}$ & 0.710 & $<0.001^{*}$ \\
\hline Weight & 0.198 & 0.233 & & \\
\hline BMI & 0.015 & 0.928 & & \\
\hline SMM & 0.625 & $<0.001^{*}$ & & \\
\hline SMI & 0.557 & $<0.001^{*}$ & & \\
\hline
\end{tabular}

HGS: hand grip strength, BMI: body mass index, SMM: skeletal muscle mass, SMl: skeletal muscle index.

a) Variables with $\mathrm{p}<0.05$ in the univariate analysis and age at the fist adjuvant chemotherapy session were included in the multivariate analysis.

${ }^{*} p<0.05$ is significant.

fered with maintaining continuous physical activity. Subjects in this study were treated with adjCTX every 3 weeks. Their physical status was usually impaired within the first week, and subsequently, the patients slowly recovered. These repeated changes in physical condition for several months made it difficult for the patient to stay active.

Although no increase of HGS persisted, no sharp decrease in HGS was observed during the follow-up period. This seemed to be because the follow-up period was as short as 6 months in this study. However, if it was long term follow-up, it was difficult to expect the maintenance of HGS. Unlike this study, several studies comparing before and after adjCTX showed that HGS significantly decreased after treatment. ${ }^{13,17}$ In addition, subsequent HT resulted in a sus- tained decrease in HGS. ${ }^{14}$ This decrease in HGS was bilateral suggesting a relationship with systemic muscle wasting. The long term decline in muscle strength is worrisome because low muscle strength could lead to a persistent reduction in quality of life. ${ }^{18}$ Therefore, periodic assessments of HGS should pay attention to muscle weakness and provide feedback to encourage exercise participation.

The results showed that the HGS of the affected side tended to be lower than that of the contralateral side, but no significant difference was observed. In addition, a previous study reported that there was a clear difference in shoulder function between both sides, but the difference in HGS was not clear. ${ }^{19}$ Similar to the HGS of the unaffected 
Table 4. Univariate and multivariate linear regression analysis of hand grip strength of the unaffected side at 6 months

\begin{tabular}{|c|c|c|c|c|}
\hline \multirow{2}{*}{ Variables } & \multicolumn{2}{|c|}{ Univariate analysis } & \multicolumn{2}{|c|}{ Multivariate analysis $\left.(n=38)^{a}\right)$} \\
\hline & Standardized Beta & $\mathrm{p}$-value & Standardized Beta & p-value \\
\hline \multicolumn{5}{|l|}{ Baseline } \\
\hline Age & -0.316 & 0.053 & & \\
\hline Height & 0.433 & $0.007^{\star}$ & & \\
\hline HGS of the affected side & 0.668 & $<0.001^{*}$ & & \\
\hline HGS of the unaffected side & 0.791 & $<0.001^{*}$ & & \\
\hline Weight & 0.283 & 0.090 & & \\
\hline BMI & 0.008 & 0.961 & & \\
\hline SMM & 0.392 & $0.016^{*}$ & & \\
\hline SMI & 0.130 & 0.444 & & \\
\hline \multicolumn{5}{|l|}{3 weeks } \\
\hline HGS of the affected side & 0.757 & $<0.001^{*}$ & -0.605 & $<0.001^{*}$ \\
\hline HGS of the unaffected side & 0.857 & $<0.001^{*}$ & 0.754 & $<0.001^{*}$ \\
\hline Weight & 0.284 & 0.084 & & \\
\hline $\mathrm{BMI}$ & 0.033 & 0.846 & & \\
\hline SMM & 0.382 & $0.018^{*}$ & & \\
\hline SMI & 0.119 & 0.478 & & \\
\hline \multicolumn{5}{|l|}{2 months } \\
\hline HGS of the affected side & 0.735 & $<0.001^{*}$ & & \\
\hline HGS of the unaffected side & 0.849 & $<0.001^{*}$ & & \\
\hline Weight & 0.324 & $0.047^{*}$ & & \\
\hline BMI & 0.043 & 0.797 & & \\
\hline SMM & 0.660 & $<0.001^{*}$ & & \\
\hline SMI & 0.415 & $0.010^{*}$ & & \\
\hline \multicolumn{5}{|l|}{6 months } \\
\hline HGS of the affected side & 0.828 & $<0.001^{*}$ & 0.660 & $<0.001^{*}$ \\
\hline Weight & 0.346 & $0.033^{*}$ & & \\
\hline BMI & 0.094 & 0.574 & & \\
\hline SMM & 0.772 & $<0.001^{*}$ & 0.197 & $<0.026^{\star}$ \\
\hline SMI & 0.659 & $<0.001^{*}$ & & \\
\hline
\end{tabular}

HGS: hand grip strength, BMI: body mass index, SMM: skeletal muscle mass, SMl: skeletal muscle index.

a) Variables with $p<0.05$ in the univariate analysis and age at the fist adjuvant chemotherapy session were included in the multivariate analysis.

${ }^{*} p<0.05$ is significant.

side, HGS of the affected side showed a relatively large recovery during the first 3 weeks. These results showed the interrelationship between bilateral sides in postoperative recovery. However, in the long term, a continuous recovery of the affected side might be difficult. Even aggressive exercise intervention after radiotherapy could not recover HGS degradation of the affected side in an 18-month followup. ${ }^{20}$ It might be caused by delayed participation after several months after surgery, so starting exercise immediately after surgery is expected to help maintain HGS. However, no studies have been conducted on the effects of early exercise participation on HGS, so further studies are needed. Clinically active participation in exercise is already recommended immediately after surgery in BCS. ${ }^{16,21}$ Moreover, in that muscle weakness progresses to both sides, it is desirable to exercise the whole body and not a specific limb.

In this study, we analyzed the factors related to high HGS at the endpoint (6 months after adjCTX start). First, HGS of the unaffected side at 3 weeks and 2 months was positively related to HGS at 6 months. Additionally, a previous study with a 7-year long term follow-up reported that HGS and arm abduction strength at 6 weeks postoperatively correlated with values after 7 years. ${ }^{11}$ Maintaining high perioperative HGS seemed to be an important factor for longterm recovery. In addition, our study found that HGS between the affected and unaffected sides was highly correlated at 6 months. Similar to the results in the analysis of changes in HGS, it can be es- 
timated that both hands have a tendency to recover together.

However, HGS of the affected side at 6 months was negatively correlated with the contralateral HGS at 3 weeks while it was positively correlated with the contralateral HGS at 6 months. Interestingly, the same result was observed in the unaffected side. It is difficult to know why, but if one hand is weak at first, it may be the result of trying to use more of the other. This result appeared to be another effect of the interrelationship between the two upper limbs. Further research might be necessary in this regard.

The 6-month SMM was also associated with the HGS of the unaffected side indicating that high HGS and muscle mass may be related. However, it is controversial whether there is a direct relationship between muscle strength and muscle mass in cancer patients. ${ }^{22-24}$ Moreover, the previous mediation analysis study for BCS showed that HGS and SMM were not directly related. ${ }^{23}$ However, apart from this correlation, it is well-known that low SMM is related to survival, surgical complications, and treatment-related toxicity. ${ }^{25}$ In addition, a prospective cohort study revealed an association between sarcopenia and high all-cause mortality in BCS. ${ }^{26}$ Therefore, it is important to maintain a high SMM, regardless of the relationship with HGS.

In the general population, it is known that anthropometric factors are significantly associated with HGS. ${ }^{27}$ But, in this study, multivariate regression analysis showed no significant association between anthropometric factors and HGS at 6 months. In fact, the association between anthropometric factors and the prognosis of breast cancer patients is a controversial issue. Some studies have described anthropometric factors as prognostic factors for disease recurrence and reduced overall survival. ${ }^{28,29}$ However, other studies have not confirmed the prognostic role of BMI. ${ }^{30,31}$ In this study, the association between anthropometric factors and early postoperative HGS was less relevant in BCS than in the general population. Possible reasons seemed that cancer-related risk factors and various cancer treatments might have more impact than anthropometric factors.

However, unexpectedly, in the additional analysis of breast cancer related factors, a few factors such as TT had a significant correlation with HGS. HGS of the unaffected side at 6 months was significantly low in subjects treated with TT. TT was frequently used as maintenance treatment after adjCTX, often delivered for long periods. ${ }^{32}$ Although TT was rarely related to musculoskeletal complications, ${ }^{32}$ long-term treatment could hinder participation in physical activity. Although, until now, the exercise-related intervention was focused on patients who underwent adjCTX and radiation, ${ }^{33}$ our results suggest the patients undergoing TT should be encouraged to exercise.

Patients who underwent breast reconstruction together with breast cancer surgery and who did not receive radiotherapy had also lower ipsilateral HGS. According to a systematic review, radiation bring out delayed musculoskeletal complications, and long-term follow-up showed an odd ratio of 1.70-6.83 for radiotherapy as a risk factor for muscle strength loss. ${ }^{34}$ Our study is not a long-term observation, but, unlike previous studies, it does not imply that radiation has a positive effect. Contrarily, since all subjects of this study undergoing breast reconstruction did not received radiation, the results showed that reconstruction had a greater adverse effect on HGS than radiation. Therefore, it might be necessary to pay more attention to BCS who underwent breast reconstruction.

This study has several limitations. First, the number of subjects included in the analysis was small. Particularly BCS in this study underwent various treatments according to different regimens. Furthermore, HGS differed depending on the laterality and dominant handedness. Unfortunately, because of the small sample size, detailed subgroup analysis could not be performed. Additionally, the relationship between socioeconomic statuses was analyzed, but since there are very few cases in several sub-variables, the results were limited by the proof of relevance. Also, in terms of retrospective research, the objectivity of the data was limited and it was difficult to control for all confounding factors. In addition, the preoperative and postoperative changes could not be confirmed because the preoperative condition was not evaluated. Finally, it was difficult to explain the long-term prognosis and relevance because the followup period was short, only about 6 months.

In conclusion, this follow-up study showed that a significant increase in HGS on the unaffected side within the early stages of adjCTX. This result seemed to mean that the inherent power to recover the physical condition is present even in subsequent adjCTX. And it seemed that there might be interrelationships between both upper extremities in physical recovery. In addition, since TT and breast construction was significantly associated with the HGS, there is a need for exercise-related intervention in patients undergoing such treatment. 


\section{REFERENCES}

1. Li N, Deng Y, Zhou L et al. Global burden of breast cancer and attributable risk factors in 195 countries and territories, from 1990 to 2017: results from the Global Burden of Disease Study 2017. J Hematol Oncol. 2019;12(1):140.

2. Hassanipour S, Maghsoudi A, Rezaeian S et al. Survival rate of breast cancer in eastern mediterranean region countries: a systematic review and meta-analysis. Ann Glob Health. 2019;85(1):138.

3. Olsson Moller U, Beck I, Ryden L et al. A comprehensive approach to rehabilitation interventions following breast cancer treatment - a systematic review of systematic reviews. BMC Cancer. 2019;19(1):472.

4. Cooney MA, Culleton-Quinn E, Stokes E. Current knowledge of pain after breast cancer treatment: a systematic review. Pain Manag Nurs. 2013;14(2):110-23.

5. Bower JE, Ganz PA, Desmond KA et al. Fatigue in breast cancer survivors: occurrence, correlates, and impact on quality of life. J Clin Oncol. 2000;18(4):743-53.

6. Maass SW, Roorda C, Berendsen AJ et al. The prevalence of long-term symptoms of depression and anxiety after breast cancer treatment: a systematic review. Maturitas. 2015;82(1):100-8.

7. Keesing S, Rosenwax L, McNamara B. The implications of women's activity limitations and role disruptions during breast cancer survivorship. Womens Health. 2018;14:1745505718756381.

8. Deluche E, Leobon S, Desport JC et al. Impact of body composition on outcome in patients with early breast cancer. Support Care Cancer. 2018;26(3):861-8.

9. Gomes PR, Freitas Junior IF, da Silva CB et al. Short-term changes in handgrip strength, body composition, and lymphedema induced by breast cancer surgery. Rev Bras Ginecol Obstet. 2014;36(6):244-50.

10. Harrington S, Padua D, Battaglini C et al. Upper extremity strength and range of motion and their relationship to function in breast cancer survivors. Physiother Theory Pract. 2013;29(7):513-20.

11. Kootstra JJ, Dijkstra PU, Rietman H et al. A longitudinal study of shoulder and arm morbidity in breast cancer survivors 7 years after sentinel lymph node biopsy or axillary lymph node dissection. Breast Cancer Res Treat. 2013;139(1):125-34.

12. Espana Romero V, Ortega FB, Vicente Rodriguez G et al. Elbow position affects handgrip strength in adolescents: validity and reliability of Jamar, DynEx, and TKK dynamometers. J Strength Cond Res. 2010;24(1):272-7.

13. Klassen O, Schmidt ME, Ulrich CM et al. Muscle strength in breast cancer patients receiving different treatment regimes. J Cachexia Sarcopenia Muscle. 2017;8(2):305-16.

14. Van der Weijden Van Doornik EM, Slot DE, Burtin C et al. Grip strength in women being treated for breast cancer and receiving adjuvant endocrine therapy: systematic review. Phys Ther. 2017;97(9):904-14.

15. De Groef A, Geraerts I, Demeyer H et al. Physical activity levels after treatment for breast cancer: two-year follow-up. Breast. 2018;40:23-8.

16. Visovsky C. Muscle strength, body composition, and physical activity in women receiving chemotherapy for breast cancer. Integr Cancer Ther. 2006;5(3):183-91.

17. Perez CS, das Neves LMS, Vacari AL et al. Reduction in handgrip strength and electromyographic activity in women with breast cancer. J
Back Musculoskelet Rehabil. 2018;31(3):447-52.

18. Winters Stone KM, Bennett JA, Nail L et al. Strength, physical activity, and age predict fatigue in older breast cancer survivors. Oncol Nurs Forum. 2008;35(5):815-21.

19. Merchant CR, Chapman T, Kilbreath SL et al. Decreased muscle strength following management of breast cancer. Disabil Rehabil. 2008;30(15):1098-105.

20. Ibrahim M, Muanza T, Smirnow N et al. A pilot randomized controlled trial on the effects of a progressive exercise program on the range of motion and upper extremity grip strength in young adults with breast cancer. Clin Breast Cancer. 2018;18(1):e55-e64.

21. McNeely ML, Binkley JM, Pusic AL et al. A prospective model of care for breast cancer rehabilitation: postoperative and postreconstructive issues. Cancer. 2012;118(8 Suppl):2226-36.

22. Adams SC, Segal RJ, McKenzie DC et al. Impact of resistance and aerobic exercise on sarcopenia and dynapenia in breast cancer patients receiving adjuvant chemotherapy: a multicenter randomized controlled trial. Breast Cancer Res Treat. 2016;158(3):497-507.

23. Benavides Rodriguez L, Garcia Hermoso A, Rodrigues Bezerra D et al. Relationship between handgrip strength and muscle mass in female survivors of bnreast cancer: A Mediation Analysis. Nutrients. 2017;9(7).

24. Biolo G, Di Girolamo FG, Breglia A et al. Inverse relationship between "a body shape index" (ABSI) and fat-free mass in women and men: insights into mechanisms of sarcopenic obesity. Clin Nutr. 2015;34(2):323-7.

25. Cespedes Feliciano E, Chen WY. Clinical implications of low skeletal muscle mass in early-stage breast and colorectal cancer. Proc Nutr Soc. 2018;77(4):382-7.

26. Villasenor A, Ballard-Barbash R, Baumgartner K et al. Prevalence and prognostic effect of sarcopenia in breast cancer survivors: the HEAL Study. J Cancer Surviv. 2012;6(4):398-406.

27. Kim CR, Jeon YJ, Kim MC et al. Reference values for hand grip strength in the South Korean population. PLoS One. 2018;13(4):e0195485.

28. Arce-Salinas C, Aguilar-Ponce JL, Villarreal-Garza C et al. Overweight and obesity as poor prognostic factors in locally advanced breast cancer patients. Breast Cancer Res Treat. 2014;146(1):183-8.

29. Herlevic VC, Mowad R, Miller JK et al. Breast cancer outcomes in a population with high prevalence of obesity. J Surg Res. 2015;198(2):371-6.

30. Gennari A, Amadori D, Scarpi E et al. Impact of body mass index (BMI) on the prognosis of high-risk early breast cancer (EBC) patients treated with adjuvant chemotherapy. Breast Cancer Res Treat. 2016;159(1):79-86.

31. Chan DS, Vieira AR, Aune D et al. Body mass index and survival in women with breast cancer-systematic literature review and meta-analysis of 82 follow-up studies. Ann Oncol. 2014;25(10):1901-14.

32. Sodergren SC, Copson E, White A et al. Systematic review of the side effects associated with anti-HER2-targeted therapies used in the treatment of breast cancer, on behalf of the EORTC quality of life group. Target Oncol. 2016;11(3):277-92.

33. Fairman CM, Focht BC, Lucas AR et al. Effects of exercise interventions during different treatments in breast cancer. J Community Support Oncol. 2016;14(5):200-9.

34. Levangie PK, Drouin J. Magnitude of late effects of breast cancer treatments on shoulder function: a systematic review. Breast Cancer Res Treat. 2009;116(1):1-15. 